\title{
Tyrosine-Protein Kinase Fer
}

National Cancer Institute

\section{Source}

National Cancer Institute. Tyrosine-Protein Kinase Fer. NCI Thesaurus. Code C18026.

Tyrosine-protein kinase Fer ( $822 \mathrm{aa}, \sim 95 \mathrm{kDa}$ ) is encoded by the human FER gene. This protein plays a role in tyrosine phosphorylation, receptor signaling and cytoskeleton reorganization. 